\title{
Development of a Guide To Recommended Audiovisual Materials on Diabetes, 1983
}

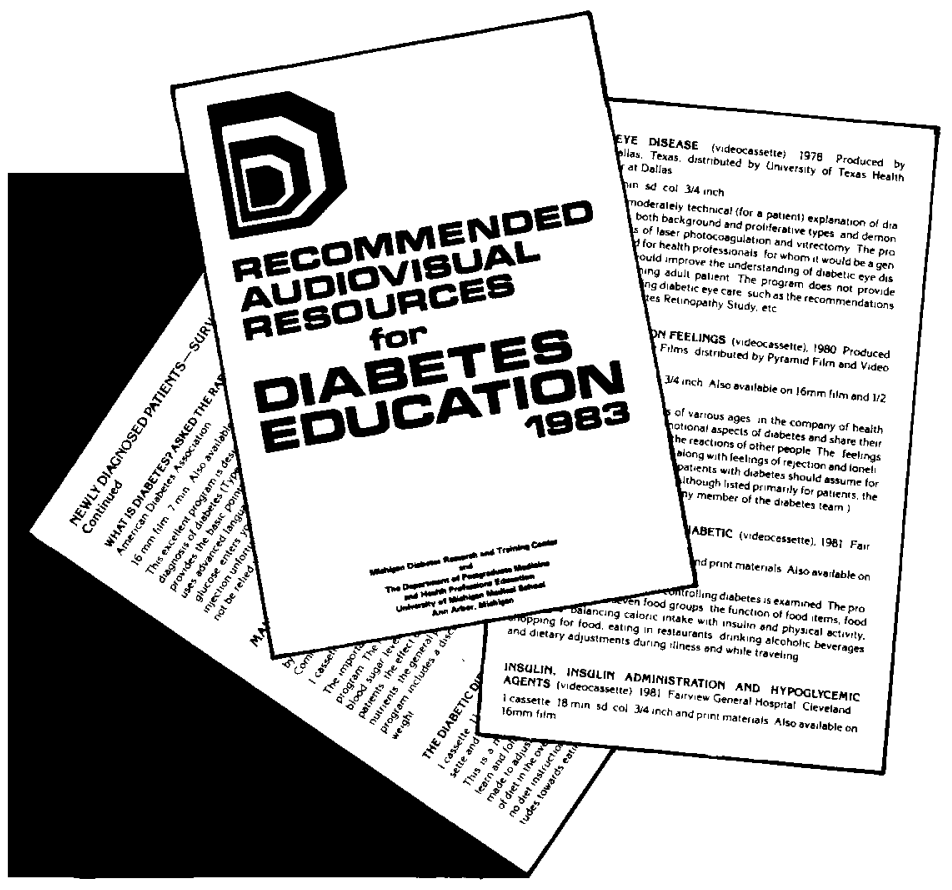

fied and catalogued in the Audiovisual Resources for Diabetes, 4th Edition. ${ }^{1}$ This is the basic reference document for diabetes audiovisual programs used by the National Diabetes Information Clearinghouse. However, the individual user such as a busy patient educator, wishing to select and obtain specific programs from the hundreds listed, faces an overwhelming task of program preview and critique. In addition, large numbers of catalogued programs were produced for a specific local purpose and prove inappropriate for generalized use. The individual user finds this out only after time-consuming preview.

To assist the many users of educational audiovisual materials the professional staff (medical, nursing, education) of the Outreach Core of the Michigan Diabetes Research and Training Center (DRTC) undertook the review and critique of these programs. The objective was compilation of a select list to be published in a booklet called "Recommended Audiovisual Resources for Diabetes Educamat produced for patient and professional education in diabetes are classi- tion, 1983" " for use by diabetes educators.

\section{Methods}

All programs listed in the catalog, Audiovisual Resources for Diabetes, 4th Edition, which met the selection criteria (see Table l) were ordered for preview (157 programs). Each was viewed and reviewed by three to five members of the professional staff of the outreach core of the Michigan DRTC (physicians, nurses, and educators) at group sessions. Practice sessions were conducted to coordinate observance of the review criteria. The review criteria are listed in Table II. The mean score from all reviewers was computed for each criteria for each program.

After all programs were reviewed, critiqued, and classified for patient or

\footnotetext{
*The booklet is available, free of charge, from Michigan Diabetes Research and Training Center, University of Michigan Medical School, Ann Arbor, MI 48109.
} 
professional education, they were further classified according to group within each category. (Table III)

\section{Results}

A total of 105 programs were reviewed by seven reviewers. An additional 52 were requested for review as they were thought to meet the selection criteria but did not; e.g., length of program was not indicated and actually was more than 30 minutes, or the production date was unknown and was prior to 1978 - another problem for the busy educator. There were no significant differences between ratings by various reviewers.

The consensus of the Overall Rating of these 105 programs showed slightly more than one-fourth $(26 \%)$ rated excellent or very good, another $14 \%$ rated good, while $60 \%$ were considered to be only fair or poor (see Figure 1).

The overall rating correlated highly (.8) with both interest and applicability to the target audience. The major predictor of overall rating was interest for the target audience, accounting for $67 \%$ of the variance. Second in importance was applicability to the target audience, accounting for an additional $7 \%$ of the variability in overall ratings. Production quality was the third most important predictor accounting for an additional $2 \%$, while accuracy accounted for another $1.5 \%$ of the variance. Surprisingly, accuracy correlated only .6 with the overall rating. A program might be very accurate but dull, not holding the viewer's interest, or very accurate but not appropriate for the intended target audience.

All programs which received an overall rating of "excellent" or "very good" were selected for the booklet. If an important topic had no programs with excellent or very good ratings, a program rated "good" was included, but only for that circumstance. Of the 105 programs which met the selection criteria, one-third were ultimately chosen for inclusion. Descriptions of these 35 programs along with information pertaining to format, length of time, producer, date of production, and distributor are included in the booklet, "Recommended Audiovisual Resources for Diabetes Education."

\section{Discussion}

The list of recommended audio-
Figure 1

Ratings of Programs

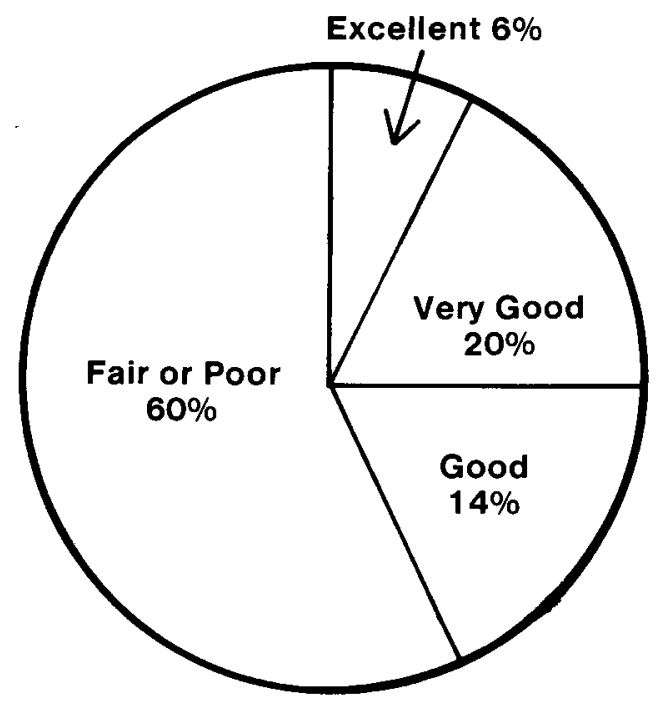

Table I

Table II

Criteria Used to Select

Programs for Review

1. Produced since 1978.

2. 30 minutes or less in length.

3. Available for loan, rental or purchase to any potential user.

4. Appropriate for practicing health professionals, or patients with diabetes.

Table III

Classification of Programs by Audience

\begin{tabular}{|l|c|}
\hline A. Patient Education & 25 \\
\hline 1. Newly Diagnosed Patients - Survival & 4 \\
\hline 2. Maintenance Program - Adult & 11 \\
\hline 3. Maintenance Program - Youth & 3 \\
\hline 4. Procedures and Techniques & 7 \\
\hline B. Professional Education & $\mathbf{1 0}$ \\
\hline 1. Diabetes Team (MD, RN, RD) & 6 \\
\hline 2. Diabetes Educators & 4 \\
\hline TOTAL & $\mathbf{3 5}$ \\
\hline
\end{tabular}

visual programs for diabetes education was developed to assist the many users of these educational programs in making selections from the hundreds available. Most educators do not have the time necessary to review a large number of programs looking for one which meets their needs. In addition, review incurs the preview charges and is associated with the frustration of ordering delays, out-of-date material and many programs that are inappropriate for one reason or another. We found 52 programs which 